\title{
Metformin use in type 2 diabetic patients is not associated with lower arterial stiffness
}

Citation for published version (APA):

Driessen, J. H. M., de Vries, F., van Onzenoort, H. A. W., Schram, M. T., van der Kallen, C., Reesink, K. D., Sep, S., Stehouwer, C. D. A., Schaper, N., Kroon, A. A., Schalkwijk, C., van den Bergh, J. P. W., \& Henry, R. M. A. (2019). Metformin use in type 2 diabetic patients is not associated with lower arterial stiffness: the Maastricht Study. Journal of Hypertension, 37(2), 365-371. https://doi.org/10.1097/HJH.0000000000001892

Document status and date:

Published: 01/02/2019

DOI:

10.1097/HJH.0000000000001892

Document Version:

Publisher's PDF, also known as Version of record

Document license:

Taverne

Please check the document version of this publication:

- A submitted manuscript is the version of the article upon submission and before peer-review. There can be important differences between the submitted version and the official published version of record.

People interested in the research are advised to contact the author for the final version of the publication, or visit the DOI to the publisher's website.

- The final author version and the galley proof are versions of the publication after peer review.

- The final published version features the final layout of the paper including the volume, issue and page numbers.

Link to publication

\footnotetext{
General rights rights.

- You may freely distribute the URL identifying the publication in the public portal. please follow below link for the End User Agreement:

www.umlib.nl/taverne-license

Take down policy

If you believe that this document breaches copyright please contact us at:

repository@maastrichtuniversity.nl

providing details and we will investigate your claim.
}

Copyright and moral rights for the publications made accessible in the public portal are retained by the authors and/or other copyright owners and it is a condition of accessing publications that users recognise and abide by the legal requirements associated with these

- Users may download and print one copy of any publication from the public portal for the purpose of private study or research.

- You may not further distribute the material or use it for any profit-making activity or commercial gain

If the publication is distributed under the terms of Article $25 \mathrm{fa}$ of the Dutch Copyright Act, indicated by the "Taverne" license above, 


\title{
Original Article
}

\section{Metformin use in type 2 diabetic patients is not associated with lower arterial stiffness: the Maastricht Study}

\author{
Johanna H.M. Driessen ${ }^{a, b, c, d}$, Frank de Vries ${ }^{a, c, d, e}$, Hein A.W. van Onzenoort ${ }^{c, f}$, \\ Miranda T. Schram ${ }^{g, h}$, Carla van der Kallen ${ }^{g, h}$, Koen D. Reesink ${ }^{i, j}$, Simone Sep ${ }^{g, h}$, \\ Coen D.A. Stehouwer ${ }^{g, h}$, Nicolaas Schaper ${ }^{g, h}$, A.A. Kroon ${ }^{g, h}$, Casper Schalkwijk ${ }^{g, h}$, \\ Joop P.W. van den Bergh ${ }^{k, l, m}$, and Ronald M.A. Henry ${ }^{g, h, j}$
}

\begin{abstract}
Introduction: Type 2 diabetes (T2D) is associated with cardiovascular disease complications such as myocardial infarction and stroke. These complications are at least partially the consequence of diabetes-associated increased arterial stiffness. Metformin, a first choice oral glucoselowering drug, has been associated with potential cardioprotective effects. However, there are no data on the association between real-life metformin use and arterial stiffness. The objective of the current study is to investigate in a population-based sample of individuals with T2D the association between metformin use and aortic stiffness (i.e. carotid-femoral pulse wave velocity, (fPWV) and carotid stiffness [i.e. carotid distensibility coefficient and Young's elastic modulus (YEM)].
\end{abstract}

Methods: We used data from The Maastricht Study, an ongoing observational prospective population-based cohort study (current $N=3451$ ). All participants with $T 2 D$, based on pharmacy records $(N=672,31.3 \%$ women, mean age $62.6 \pm 7.7)$, were included in the current study. Linear regression analyses were used to study the association between current metformin use and CfPWV, distensibility coefficient and YEM, as compared with no metformin use. Furthermore, metformin use was stratified by cumulative dose (in grams), continuous duration of use (in days), average daily dose (in grams) and time since first prescription (in years). Regression coefficients of distensibility coefficient were multiplied by -1 , consequently, for all arterial stiffness indices, a positive regression coefficient signifies increasing arterial stiffness.

Results: Linear regression showed that neither current metformin use was associated with cfPWV [adjusted $B$ : $-0.04(-0.11$ to 0.02$)$ ] nor metformin use was as stratified by cumulative dose, by continuous duration of use, by average daily dose or by time since first prescription. Metformin use was statistically significantly associated with higher carotid stiffness as assessed by distensibility coefficient $[0.12(0.01$ to 0.23$)]$, but not with YEM [0.10 (-0.03 to 0.22)]. However, there was no consistent pattern with the different stratifications of metformin use when further investigating the association with distensibility coefficient.
Conclusion: We showed that there is no significant association between current metformin use and aortic stiffness, regardless of how metformin use in itself was defined. In addition, metformin use was not associated with a lower carotid stiffness. The present results showed no beneficial effect of metformin use, dosage or duration on arterial stiffness in middle-aged patients with T2D. Alternatively, metformin may exerts its cardio-protective effects via other pathways.

Keywords: carotid artery, distensibility, metformin use, pulse wave velocity

Abbreviations: AGE, advanced glycation end-product; ATC, anatomical therapeutical chemical; cfPWV, carotidfemoral pulse wave velocity; CVD, cardiovascular disease; $\mathrm{DDD}$, defined daily dosage; $\mathrm{HbA} 1 \mathrm{c}$, glycated haemoglobin A1C; MAP, mean arterial pressure; T2D, type 2 diabetes; YEM, Young's elastic modulus

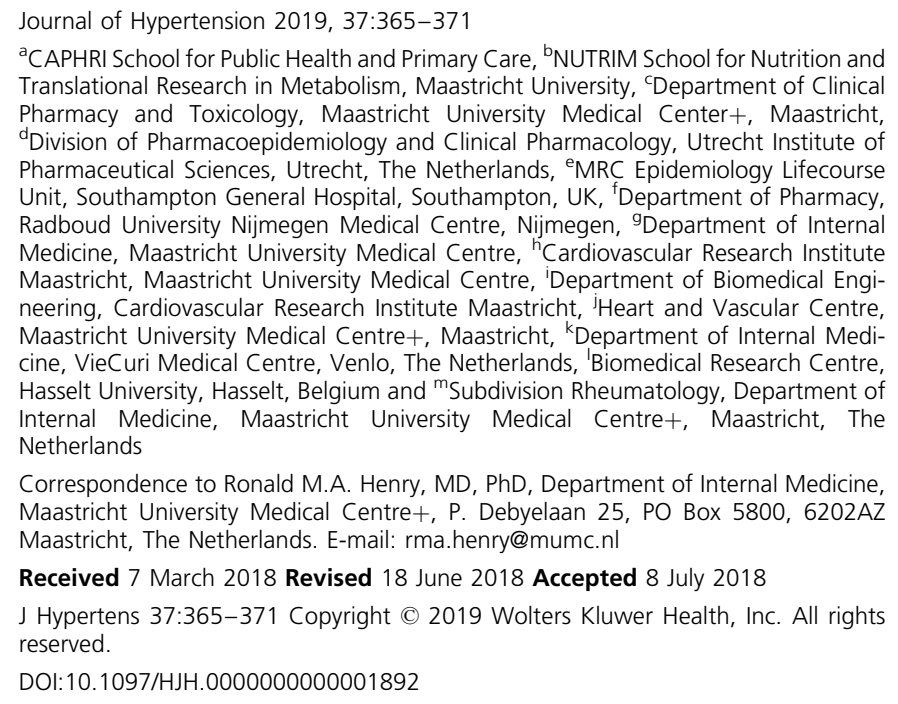




\section{INTRODUGTION}

I n the year 2030, 439 million individuals will suffer from type 2 diabetes (T2D), which will be followed by an epidemic of related cardiovascular disease (CVD) complications such as myocardial infarction (MI) and stroke [1]. These complications are, at least partially, the consequence of increased arterial stiffness [2-4], as increased arterial stiffness ultimately leads to increased SBP and decreased DBP, which hampers coronary perfusion and increases the pulsatile pressure load on the cerebral (micro-)circulation [5].

The oral glucose-lowering drug metformin is a first choice therapeutic agent in the treatment of T2D [6]. Interestingly, it has been suggested that metformin use may protect against CVD. One pathway via which metformin use may reduce CVD is via an effect on arterial stiffness [7-12].

However, how metformin may do so remains largely unknown. It has been suggested that metformin interferes with the formation of advanced glycation end-products (AGEs), thereby preventing cross-linkage of the pressure load-bearing elements of the arterial wall by AGEs [2,13,14]. Alternatively, it has been suggested that metformin may interfere with endothelial dysfunction, chronic low-grade inflammation and/or increased oxidative stress [6,15]. These phenomena are all associated with increased arterial stiffness. Currently, there are no data in the population at large on the association between metformin use and arterial stiffness, including both aortic and carotid stiffness.

In view of the above, we set out to investigate in a population-based sample of individuals with T2D the association between metformin use and aortic stiffness (i.e. carotid-femoral pulse wave velocity, cfPWV) and carotid stiffness [i.e. carotid distensibility coefficient and Young's elastic modulus (YEM)]. Metformin use (yes versus no) was further stratified according to cumulative dose (in grams), continuous duration of use (in days), average daily dose (in grams) and time since first prescription (in years). We compared metformin use with nonuse.

\section{METHODS}

We used data from The Maastricht Study, an observational prospective population-based cohort study. The rationale and methodology have been described elsewhere [16]. In brief, the study focuses on the cause, pathophysiology, complications and comorbidities of T2D and is characterized by an extensive phenotyping approach. Eligible for participation were all individuals aged between 40 and 75 years and living in the southern part of the Netherlands. Participants were recruited through mass media campaigns and from the municipal registries and the regional Diabetes Patient Registry via mailings. Recruitment was stratified according to known T2D status, with an oversampling of individuals with T2D, for reasons of efficiency.

To investigate the association between metformin use and arterial stiffness we included all participants with T2D, enrolled between November 2010 and September 2013, and for whom pharmacy data was available $(N=672)$. Pharmacy data were available up to the date of the first visit at the Maastricht Study. Patients were classified as having T2D if they had a dispensing of an antihyperglycemic drug [anatomical therapeutical chemical (ATC) A10 [17]] in the 6 months before the first visit (patients with type 1 diabetes mellitus were excluded). Based on the pharmacy dispensing data patients were classified as a current metformin or nonmetformin user. Current metformin users were initially selected as having at least one metformin dispensing in 6 months prior to the first study visit according to pharmacy dispensing records.

The examinations of each participant were performed within a time window of 3 months. The cfPWV measurements were performed during the second visit, which was for the majority of the patients within 8-14 days after their first visit. The study has been approved by the institutional medical ethical committee (NL31329.068.10) and the Minister of Health, Welfare and Sports of the Netherlands (Permit 131088-105234-PG). All participants gave written informed consent.

\section{Pharmacy dispensing records}

Dispensing records were collected at 25 loco-regional pharmacies for all participants who gave written informed consent for the collection of their drug dispensing history. Dispensing data (available from 1 January 1991) contained product name, ATC code [17], amount and date dispensed, and the prescribed dosage regimen. For current metformin users all prescriptions before the first study visit were extracted. For every prescription, the total amount of defined daily dosage (DDD) was calculated. If the DDD could not be calculated the median DDD was assigned (0.07\% of the prescriptions). The cumulative dose was estimated by adding all prescribed doses of metformin (in DDDs). The average daily dose was determined as the cumulative amount of DDDs divided by the time between the first metformin prescription and the date of the study visit. To determine the continuous duration of use we calculated the expected end date for every metformin prescription by dividing the total number of prescribed tablets over the number of tablets prescribed per day and adding this to the dispensing date. When the expected end date could not be estimated the median duration was added to determine the expected end date. A gap of 30 days between the estimated end date of a prescription and the date of the next prescription was allowed for a prescription to count as continuous use [18]. Continuous duration of use was then defined as the time between the first prescription that fulfilled this criteria and the date of the first study visit.

\section{Arterial stiffness measurements}

All measurements were done by trained vascular technicians unaware of the participants' clinical or diabetes status, in a dark, quiet temperature controlled room $\left(21-23^{\circ} \mathrm{C}\right)$. Participants were asked to refrain from smoking and drinking coffee or tea or alcoholic beverages $3 \mathrm{~h}$ prior to the study. Participants were allowed to have a light meal [breakfast and(or) lunch]. All measurements were performed in supine position after $10 \mathrm{~min}$ of rest. Talking or sleeping was not allowed during the examination. During the vascular measurements (approximately $45 \mathrm{~min}$ ), brachial systolic, diastolic, 
and mean arterial pressure (MAP) were determined every 5 min with an oscillometric device (Accutorr Plus; Datascope Inc., Montvale, New Jersey, USA). A three-lead ECG was recorded continuously during the measurements to facilitate automatic signal processing.

\section{Carotid-to-femoral pulse wave velocity}

cfPWV was determined according to recent guidelines [19] with the use of applanation tonometry (SphygmoCor; Atcor Medical, Sydney, Australia). Pressure waveforms were determined at the right common carotid and right common femoral arteries. Difference in the time of pulse arrival from the R-wave of the ECG between the two sites (transit time) was determined with the intersecting tangents algorithm. The pulse wave travel distance was calculated as $80 \%$ of the direct straight distance (measured with an infantometer) between the two arterial sites. The median of three consecutive cfPWV (defined as travelled distance/transit time) recordings was used in the analyses.

\section{Local arterial elastic properties}

Measurements were done at the left common carotid $(10 \mathrm{~mm}$ proximal to the carotid bulb), the right common femoral (10$20 \mathrm{~mm}$ proximal to the flow divider) and the right brachial (20 $\mathrm{mm}$ proximal to the antecubital fossa) arteries, with the use of an ultrasound scanner equipped with a 7.5-MHz linear probe (MyLab 70; Esaote Europe B.V., Maastricht, The Netherlands). This setup enables the measurement of diameter, distension and intima-media thickness (IMT) as described previously [20,21]. Briefly, during the ultrasound measurements a B-mode image on the basis of 19 M-lines was depicted on screen and an online echo-tracking algorithm showed real-time anterior and posterior arterial wall displacements. The M-mode recordings were composed of 19 simultaneous recordings at a frame rate of $498 \mathrm{~Hz}$. The distance between the M-line recording positions was $0.96 \mathrm{~mm}$, thus, a total segment of $18.24 \mathrm{~mm}$ of each artery was covered by the scan plane. For offline processing, the radiofrequency signal was fed into a dedicated personal computer-based acquisition system (ART.LAB; Esaote Europe B.V.) with a sampling frequency of $50 \mathrm{MHz}$ Data processing was performed in MatLab (version 7.5; Mathworks, Natick, Massachusetts, USA). The distension waveforms were obtained from the radio frequency data with the use of a wall track algorithm [20]. Carotid IMT was defined as the distance of the posterior wall from the leading edge interface between lumen and intima to the leading edge interface between media and adventitia [21]. The median diameter, distension and IMT of three measurements were used in the analyses. Local arterial elastic properties were quantified by calculating the following indices [22]:

(1) Distensibility coefficient (DC)

$$
\mathrm{DC}=\frac{\left(2 \Delta D \times D+\Delta D^{2}\right)}{\left(\mathrm{PP} \times D^{2}\right)} \quad\left(10^{-3} \mathrm{kPa}^{-1}\right)
$$

(2) Young's elastic modulus (YEM) (carotid artery only)

$$
\mathrm{YEM}=\frac{D}{(\mathrm{IMT} \times \mathrm{DC})} \quad\left(10^{3} \mathrm{kPa}\right)
$$

where $D$ is arterial diameter; $\Delta D$ distension; IMT intimamedia thickness; and PP brachial pulse pressure (calculated as SBP - DBP).

Distensibility coefficient represents arterial stiffness; YEM, the stiffness of the arterial wall material at operating pressure. Note that higher values of cfPWV and YEM, but lower values of distensibility coefficient reflect greater arterial stiffness. To make the interpretation of the different indices comparable, the regression coefficients in our models (below) of distensibility coefficient were multiplied by -1 . Therefore, for all arterial stiffness indices, a positive regression coefficient signifies increasing arterial stiffness.

\section{Reproducibility}

Reproducibility was assessed in 12 individuals (six men; $60.8 \pm 6.8$ years; six T2D) who were examined by two observers at two occasions spaced 1 week apart. The intraobserver and interobserver intraclass correlation coefficients were for cfPWV 0.87 and 0.69 , respectively; for carotid distensibility coefficient 0.85 and 0.73 , respectively; and for YEM 0.72 and 0.71 , respectively.

\section{Covariates}

Weight and height were measured without shoes and wearing light clothing using a scale and stadiometer to the nearest $0.5 \mathrm{~kg}$ or $0.1 \mathrm{~cm}$ (Seca, Hamburg, Germany). BMI was calculated by dividing the weight in kilogram by the height in meters squared. CVD history, smoking status and diabetes duration were assessed by questionnaire. Participants were regarded as having a history of CVD if they reported to have had a MI, and/or cerebrovascular infarction or haemorrhage, and/or percutaneous artery angioplasty of/or vascular surgery on the coronary, abdominal, peripheral or carotid arteries. Use of lipid-modifying and antihypertensive medication was assessed during a medication interview where generic name, dose and frequency were registered. Insulin use in the 6 months before the first visit was determined based on the pharmacy dispensing data using ATC code [17] A10A. Glycated haemoglobin A1c (HbA1c), total and HDL cholesterol and triglycerides were determined as described elsewhere [16]. Glomerular filtration rate was estimated according to the Chronic Kidney Disease Epidemiology Collaboration equation based on the combination of serum creatinine and serum cystatin C [23]. Office blood pressure (BP) was determined using a noninvasive BP measurement device (Omron 705IT; Omron, Kyoto, Japan). MAP was calculated using the office BP measurements and defined as: $(\mathrm{SBP}+2 \times \mathrm{DBP}) / 3$.

\section{Statistical analysis}

Linear regression analyses were used to study the associations between metformin use and cfPWV, distensibility coefficient and YEM, as compared with nonmetformin use. All arterial stiffness indices were log transformed because of skewed distributions. Metformin use was stratified according to cumulative dose, continuous duration of use, average daily dose and time since first prescription.

We first adjusted the models for age and sex (covariates of model 1). In model 2 , the following covariates were 
added: MAP, BMI, smoking, history of CVD, use of antihypertensive medication and use of lipid modifying drugs. Moreover, HbA1c, diabetes duration, and use of insulin were added to adjust for severity of diabetes.

In addition, two sensitivity analyses were performed. First, we restricted the main analysis to patients with a cfPWV more than 10.0. As those patients are expected to have more vascular alterations which may affect the results. In the second, sensitivity analysis we further adjusted the main analysis for BP control, defined as an office BP less than $140 / 90 \mathrm{mmHg}$.

Furthermore, we compared our cfPWV data with the published BP corrected age-matched reference data [24].

A $P$ value less than 0.05 was considered statistically significant. All analyses were done with SAS 9.4 (SAS Institute Inc., Cary, North Carolina, USA).

\section{RESULTS}

In total 672 participants with T2D and pharmacy dispensing data were available for the current analyses. Due to missing values on covariates 43 patients were excluded (missing data on BMI $(n=2)$, smoking $(n=26)$, history of CVD $(n=38)$, use of antihypertensive medication $(n=1)$, use of lipid-modifying drugs $(n=1)$ and HbA1c $(n=2)$. These missing data were not mutually exclusive. Furthermore, when studying cfPWV, 122 participants were excluded due to missing values for cfPWV (due to logistic or technical reasons) which resulted in a study population of 507 participants (453 metformin users and 54 nonmetformin users). Data from 530 participants was available when studying distensibility coefficient and data from 529 participants when investigating YEM.

In Table 1, the baseline characteristics of the study population are shown. Metformin users were less often women (29.4 and 40.7\%, respectively), used more often lipid-modifying drugs (82.8 versus $70.4 \%$ ) and had on average a shorter duration of diabetes ( 5.6 versus 7.4 years) as compared with nonmetformin users.

\section{Metformin use and carotid-to-femoral pulse wave velocity}

After adjustment for age and sex (covariates of model 1), MAP, BMI, smoking, prior CVD, the use of antihypertensive medication, the use of lipid-modifying medication, HbA1c, diabetes duration and current insulin use (extra covariates in model 2), metformin use was not statistically significantly associated with lower aortic stiffness, as estimated by cfPWV [regression coefficient $(\beta)$ and $95 \%$ confidence interval: -0.04 ( -0.11 to 0.02$)$; Table 2 ; row metformin use (nonmetformin use is reference category)].

If we analysed metformin use according to cumulative dose in grams (categories $>0-1023,1024-3121$ and $\geq 3122$ ) the results showed that, after adjustment for the covariates of model 2, aortic stiffness, as estimated by cfPWV, was not statistically associated with the different categories of cumulative metformin dose Table 2; row cumulative dose).

Similar results were obtained if metformin use was analysed according to continuous duration of use (in days), average daily dose (in grams) or time since first prescription (in years).
TABLE 1. Baseline characteristics of current metformin and nonmetformin users

\begin{tabular}{|c|c|c|}
\hline & $\begin{array}{l}\text { Nonmetformin } \\
\text { users, } N=54\end{array}$ & $\begin{array}{l}\text { Metformin } \\
\text { users, } N=453\end{array}$ \\
\hline Age, years & $62.5 \pm 8.0$ & $62.6 \pm 7.4$ \\
\hline Sex (women) & $20(40.7)$ & $133(29.4)$ \\
\hline BMI $\left(\mathrm{kg} / \mathrm{m}^{2}\right)$ & $29.0 \pm 4.2$ & $29.5 \pm 4.6$ \\
\hline$<25 \mathrm{~kg} / \mathrm{m}^{2}$ & $13(24.1)$ & $71(15.7)$ \\
\hline $25-30 \mathrm{~kg} / \mathrm{m}^{2}$ & $19(35.2)$ & $193(42.6)$ \\
\hline$\geq 30 \mathrm{~kg} / \mathrm{m}^{2}$ & $22(40.7)$ & $189(41.7)$ \\
\hline \multicolumn{3}{|l|}{ Smoking status } \\
\hline Never & $13(24.1)$ & $127(28.0)$ \\
\hline Former & $29(53.7)$ & $258(57.0)$ \\
\hline Current & $12(22.2)$ & $68(15.0)$ \\
\hline History of cardiovascular disease & $17(31.5)$ & $121(26.7)$ \\
\hline Use of lipid-modifying drugs & $38(70.4)$ & $375(82.8)$ \\
\hline Use of antihypertensive drugs & $40(74.1)$ & $334(73.7)$ \\
\hline eGFR $\left(\mathrm{ml} / \mathrm{min} \text { per } 1.73 \mathrm{~m}^{2}\right)^{\mathrm{a}}$ & $81.4 \pm 21.4$ & $85.3 \pm 17.1$ \\
\hline Total cholesterol to HDL ratio & $3.8 \pm 1.3$ & $3.6 \pm 1.1$ \\
\hline Triglycerides (mmol/) & $1.8 \pm 1.3$ & $1.7 \pm 0.9$ \\
\hline $\operatorname{HbA1c}(\%)$ & $7.7 \pm 1.2$ & $7.0 \pm 1.0$ \\
\hline Diabetes duration (years) & $7.4 \pm 5.3$ & $5.6 \pm 4.1$ \\
\hline $\begin{array}{l}\text { Use of insulin in } 6 \text { months before } \\
\text { first visit }\end{array}$ & $38(70.4)$ & $101(18.6)$ \\
\hline Mean arterial pressure $(\mathrm{mmHg})$ & $97.8 \pm 13.6$ & $98.9 \pm 10.3$ \\
\hline Office SBP (mmHg) & $142.7 \pm 20.8$ & $142.2 \pm 16.8$ \\
\hline Office DBP (mmHg) & $75.4 \pm 11.8$ & $77.2 \pm 9.4$ \\
\hline Office heart rate & $70.2 \pm 12.3$ & $72.6 \pm 11.9$ \\
\hline $\operatorname{cfPWV}(\mathrm{m} / \mathrm{s})$ & $10.6 \pm 2.5$ & $9.9 \pm 2.3$ \\
\hline$D C^{c}\left(10^{-3} \mathrm{kPa}^{-1}\right)$ & $14.4 \pm 4.9$ & $13.1 \pm 4.9$ \\
\hline $\mathrm{YEM}^{\mathrm{d}}\left(10^{3} \mathrm{kPa}\right)$ & $0.7 \pm 0.3$ & $0.8 \pm 0.4$ \\
\hline
\end{tabular}

Data are presented as number (\%) of patients or mean \pm SD. cfPWV, carotid-femoral pulse wave velocity; eGFR, estimated glomerular filtration rate; $\mathrm{HbA} 1 \mathrm{c}$, glycated haemoglobin A1c.

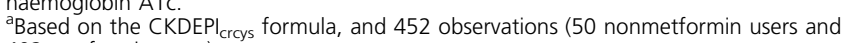
402 metformin users)

based on office SBP and DBP measurements.

'Based on 530 observations in total (57 nonmetformin users and 473 metformin users). dBased on 529 observations in total (57 nonmetformin users and 472 metformin users).

\section{Metformin use and carotid stiffness indices}

After adjustment for age and sex (covariates of model 1) and MAP, BMI, smoking, prior CVD, use of antihypertensive medication, and/or use of lipid-modifying medication, HbA1c, diabetes duration, and current insulin use (extra covariates of model 2) metformin use was statistically significantly associated with higher carotid stiffness as estimated by distensibility coefficient [0.12 (0.01-0.23); recall -1 multiplication], but not with YEM $[0.10(-0.03$ to 0.22 )] [Table 3; row metformin use (nonmetformin use is reference category)].

If we analysed metformin use according to cumulative dose in grams (categories $>0-1023,1024-3121$ and $\geq 3122$ ) the results showed that, after the adjustments for the covariates of model 2, carotid stiffness as estimated by distensibility coefficient and YEM was associated with greater stiffness for some of the cumulative dose categories, whereas there was no association with the highest cumulative dose category.

If we analysed metformin use according to continuous duration of use in days (categories 0-90, 91-547 and $\geq 548$ ), the results showed that, after the adjustments for the covariates of model 2, carotid stiffness as estimated by distensibility coefficient and YEM did not decrease with a longer period of continuous use. 
TABLE 2. Current metformin use and carotid-to-femoral pulse wave velocity

\begin{tabular}{|c|c|c|c|}
\hline & $N=507$ & $\begin{array}{c}\text { Model } 1 \\
\beta(95 \% \mathrm{Cl})\end{array}$ & $\begin{array}{c}\text { Model2 } \\
\beta(95 \% \mathrm{Cl})\end{array}$ \\
\hline \multicolumn{4}{|l|}{ Metformin use } \\
\hline No current metformin use & 54 & Reference category & Reference category \\
\hline Current metformin use & 453 & $-0.07(-0.13 \text { to }-0.01)^{*}$ & $-0.04(-0.11$ to 0.02$)$ \\
\hline \multicolumn{4}{|l|}{ By cumulative dose } \\
\hline $0-1023 \mathrm{~g}$ & 150 & $-0.08(-0.14 \text { to }-0.02)^{*}$ & $-0.00(-0.07$ to 0.07$)$ \\
\hline $1024-3121 \mathrm{~g}$ & 149 & $-0.08(-0.14 \text { to }-0.01)^{*}$ & $-0.03(-0.09$ to 0.04$)$ \\
\hline$\geq 3122 \mathrm{~g}$ & 154 & $-0.06(-0.13$ to 0.00$)$ & $-0.04(-0.11$ to 0.03$)$ \\
\hline \multicolumn{4}{|l|}{ By continuous duration of use } \\
\hline 0-90 days & 139 & $-0.05(-0.12$ to 0.01$)$ & $-0.00(-0.07$ to 0.06$)$ \\
\hline $91-547$ days & 161 & $-0.09(-0.15 \text { to }-0.02)^{*}$ & $-0.03(-0.10$ to 0.04$)$ \\
\hline$\geq 548$ days & 153 & $-0.08(-0.14 \text { to }-0.01)^{*}$ & $-0.04(-0.11$ to 0.02$)$ \\
\hline \multicolumn{4}{|l|}{ By average daily dose } \\
\hline$\leq 1.0 \mathrm{~g} /$ day & 157 & $-0.08(-0.14 \text { to }-0.01)^{*}$ & $-0.02(-0.09$ to 0.05$)$ \\
\hline $1.01-1.80 \mathrm{~g} /$ day & 147 & $-0.08(-0.15 \text { to }-0.02)^{*}$ & $-0.03(-0.10$ to 0.04$)$ \\
\hline$\geq 1.81 \mathrm{~g} /$ day & 149 & $-0.06(-0.12$ to 0.01$)$ & $-0.03(-0.09$ to 0.04$)$ \\
\hline \multicolumn{4}{|c|}{ By time since first metformin prescription } \\
\hline$<3.0$ year & 149 & $-0.09(-0.16 \text { to }-0.03)^{*}$ & $-0.04(-0.11$ to 0.04$)$ \\
\hline $3.0-4.9$ years & 114 & $-0.11(-0.18 \text { to }-0.05)^{*}$ & $-0.07(-0.14$ to 0.00$)$ \\
\hline$\geq 5.0$ years & 190 & $-0.03(-0.09$ to 0.03$)$ & $-0.01(-0.07$ to 0.06$)$ \\
\hline
\end{tabular}

$\mathrm{Cl}$, confidence interval. Model 1: adjusted for age and sex. Model 2: Model 1, mean arterial pressure, BMI, smoking, history of cardiovascular disease, use of antihypertensive medication, use of lipid-modifying medication and glycated haemoglobin A1c, diabetes duration, and current use of insulin.

*Statistically significant, $P$ value less than 0.05 .

If we analysed metformin use according to average daily dose in grams (categories $\leq 1.0,1.01-1.80$ and $\geq 1.81$ ), the results showed that, after the adjustments for the covariates of model 2, all average daily dose categories were statistically significantly associated with greater carotid stiffness as estimated by distensibility coefficient $[0.13(0.02-0.25), 0.14$ (0.03-0.26), $0.15(0.04-0.27)$ ] but not with YEM; (Table 3; row average daily dose).

Finally, if we analysed metformin use according to time since first prescription in years (categories <3.0, 3.0-4.9 and $\geq 5.0$ ) the results showed that, after adjustment for the covariates of model 2, carotid stiffness, as estimated by distensibility coefficient and YEM, did not decrease with a longer time since the first prescription.

\section{Sensitivity analyses}

Restricting our analysis to participants with a cfPWV more than 10.0 did not substantially change the results [cfPWV: 0.01 ( -0.05 to 0.05$)$, distensibility coefficient: 0.12 ( -0.28 to 0.02), YEM: 0.11 ( -0.06 to 0.28)]. Adjusting the main

TABLE 3. Current metformin use and carotid artery stiffness indices

\begin{tabular}{|c|c|c|c|c|c|c|}
\hline & \multicolumn{3}{|c|}{ Carotid artery distensibility coefficient ${ }^{\mathrm{a}}$} & \multicolumn{3}{|c|}{ Carotid artery young's elastic modulus } \\
\hline & $\mathbf{N}=\mathbf{5 3 0}$ & $\begin{array}{c}\text { Model } 1 \\
\beta(95 \% \mathrm{Cl})\end{array}$ & $\begin{array}{c}\text { Model } 2 \\
\beta(95 \% \mathrm{Cl})\end{array}$ & $N=529$ & $\begin{array}{c}\text { Model } 1 \\
\beta(95 \% \mathrm{Cl})\end{array}$ & $\begin{array}{c}\text { Model } 2 \\
\text { B }(95 \% \text { Cl) }\end{array}$ \\
\hline \multicolumn{7}{|l|}{ Metformin use } \\
\hline No current metformin use & 57 & Reference & Reference & 57 & Reference & Reference \\
\hline $\begin{array}{l}\text { Current metformin use } \\
\text { By cumulative dose }\end{array}$ & 473 & \multicolumn{4}{|c|}{ By cumulative dose } & $0.10(-0.03$ to 0.23$)$ \\
\hline $0-1023 \mathrm{~g}$ & 158 & $0.13(0.02 \text { to } 0.24)^{*}$ & $0.18(0.06 \text { to } 0.30)^{*}$ & 159 & $0.10(-0.02$ to 0.22$)$ & $0.16(0.02 \text { to } 0.29)^{*}$ \\
\hline $1024-3121 \mathrm{~g}$ & 156 & $0.12(0.02 \text { to } 0.23)^{*}$ & $0.16(0.05 \text { to } 0.27)^{*}$ & 155 & $0.13(0.01 \text { to } 0.25)^{*}$ & $0.16(0.03$ to 0.29$)$ \\
\hline$\geq 3122 \mathrm{~g}$ & 159 & $0.11(-0.00$ to 0.22$)$ & $0.11(-0.00$ to 0.22$)$ & 159 & $0.06(-0.06$ to 0.19$)$ & $0.06(-0.07$ to 0.18$)$ \\
\hline \multicolumn{7}{|c|}{ By continuous duration of use } \\
\hline $0-90$ days & 146 & $0.11(0.00 \text { to } 0.22)^{*}$ & $0.14(0.03$ to 0.26$)$ & 146 & $0.09(-0.03$ to 0.21$)$ & $0.11(-0.02$ to 0.24$)$ \\
\hline $91-547$ days & 172 & $0.17(0.06 \text { to } 0.28)^{*}$ & $0.21(0.10 \text { to } 0.32)^{*}$ & 172 & $0.16(0.04 \text { to } 0.28)^{*}$ & $0.19(0.06 \text { to } 0.31)^{*}$ \\
\hline$\geq 548$ days & 155 & $0.07(-0.04$ to 0.18$)$ & $0.09(-0.02$ to 0.20$)$ & 154 & $0.05(-0.07$ to 0.17$)$ & $0.06(-0.06$ to 0.19$)$ \\
\hline \multicolumn{7}{|l|}{ By average daily dose } \\
\hline$\leq 1.0 \mathrm{~g} / \mathrm{day}$ & 166 & $0.11(-0.00$ to 0.21$)$ & $0.13(0.02 \text { to } 0.25)^{*}$ & 166 & $0.09(-0.03$ to 0.21$)$ & $0.10(-0.02$ to 0.23$)$ \\
\hline $1.01-1.80 \mathrm{~g} /$ day & 154 & $0.11(0.00 \text { to } 0.22)^{*}$ & $0.14(0.03 \text { to } 0.26)^{*}$ & 153 & $0.09(-0.03$ to 0.22$)$ & $0.12(-0.01$ to 0.25$)$ \\
\hline$\geq 1.81 \mathrm{~g} /$ day & 153 & $0.14(0.04 \text { to } 0.25)^{*}$ & $0.15(0.04 \text { to } 0.27)^{*}$ & 153 & $0.12(-0.00$ to 0.24$)$ & $0.12(-0.01$ to 0.25$)$ \\
\hline \multicolumn{7}{|c|}{ By time since first metformin prescription } \\
\hline$<3.0$ years & 154 & $0.12(0.01 \text { to } 0.23)^{*}$ & $0.16(0.04 \text { to } 0.28)^{*}$ & 154 & $0.11(-0.01$ to 0.23$)$ & 0.15 (0.01 to 0.29$)$ \\
\hline $3.0-4.9$ years & 121 & $0.08(-0.03$ to 0.19$)$ & $0.11(-0.02$ to 0.23$)$ & 120 & $0.06(-0.06$ to 0.19$)$ & $0.09(-0.05$ to 0.22$)$ \\
\hline$\geq 5.0$ years & 198 & $0.15(0.04 \text { to } 0.25)^{*}$ & $0.15(0.04 \text { to } 0.26)^{*}$ & 198 & $0.11(-0.00$ to 0.23$)$ & $0.11(-0.02$ to 0.23$)$ \\
\hline
\end{tabular}

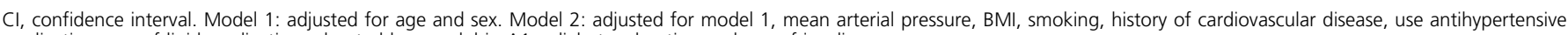
medication, use of lipid medication, glycated haemoglobin A1c, diabetes duration and use of insulin.

${ }^{a}$ Regression coefficients of carotid artery distensibility coefficient are multiplied by -1 , therefore, for all carotid stiffness indices, a positive regression coefficient signifies increasing stiffness.

${ }^{*}$ Statistically significant, $P$ value less than 0.05 . 
analysis for $\mathrm{BP}$ control did not materially change the results [cfPWV: $-0.04(-0.10$ to 0.03$)$, distensibility coefficient: 0.14 (0.04 to 0.25$)$, YEM: 0.12 ( -0.00 to 0.23$)$ ].

\section{Comparison with reference data}

At an individual level the majority (97.8\%) of the patients had a cfPWV which was in the BP corrected age-matched range (mean $\pm 2 S D$ ) of the reference values [26]. The other patients had a cfPWV higher than the BP corrected agematched range.

\section{DISGUSSION}

The results of the current study show that there is no association between current metformin use and aortic stiffness as estimated by cfPWV, regardless of how metformin use was further defined (e.g. by cumulative dose, average daily dose, continuous duration of use or time since first prescription). In addition, use of metformin was not associated with a decrease in carotid stiffness as assessed by distensibility coefficient and YEM. Counter intuitively, some individual categories of the metformin exposure were associated with greater stiffness, however no consistent pattern with the different stratifications of metformin use was found. Thereby the results of the current study do not support the hypothesis that metformin use protects against CVD by lowering arterial stiffness.

To the best of our knowledge there is currently no population-based data available on the association between use of metformin and arterial stiffness. Interestingly, our population-based data are in line with small $(n \leq 52)$ clinical trials, which studied short-term use $(\leq 52$ weeks) of metformin and various arterial stiffness parameters and showed no effect $[25,26]$.

Our study population was characterized by good glycaemic control (mean HbA1c 7.0) and well controlled hypertension $(73.9 \%$ of participants used antihypertensive drugs). As high $\mathrm{BP}$ is a prime determinant of arterial stiffness, the fact that our population was well treated might have caused an underestimation of the associations between metformin use and arterial stiffness. In addition, the majority of our study population had a cfPWV which was in the BP corrected age-matched range. It may be suggested that as a result of this there are only relatively few vascular alterations in our study population, which may be a reason why we did not found an association between use of metformin and arterial stiffness.

One of the hypothesized mechanisms how metformin might decrease arterial stiffness includes via its effect on AGEs. It has been suggested that metformin might reduce the AGEs via its antioxidative properties. Metformin treatment (100, 250 and $500 \mu \mathrm{mol} / \mathrm{l})$ reduced intracellular reactive oxygen species in human aortic endothelial cells [27]. In addition, use of metformin $(60 \mathrm{mg} / \mathrm{kg} /$ day $)$ has been associated with a reduced production of superoxide and a reduced level of $\mathrm{Ne}$-(carboxymethyl)lysine, one of the AGEs, in diabetic rats [28]. Both studies investigated metformin concentrations which do not occur in clinical practice (peak concentration is about $15 \mu \mathrm{mol} / \mathrm{l}$ in humans [29]). This observation leaves room to speculate whether animal and in-vitro results could be directly translated to T2D patients.

An alternative explanation for the fact that we did not find an association between use of metformin and cfPWV might be selection bias or confounding by disease severity. Study participation is voluntary, and it might therefore be that only relatively healthy patients with T2D, who are potentially intensively treated for cardiovascular risk factors, participated (selection bias). Yet, $26.4 \%$ of the metformin users still had a history of CVD. Disease severity may have been an important confounder in this study, as patients with a poor glycaemic control are often prescribed higher dosages of metformin and these patients might also have more arterial stiffness as a consequence of the poor glycaemic control. We tried to capture disease severity in our analyses by adjusting for duration of diabetes, use of insulin, and HbA1c. These adjustments only slightly changed the point estimates, suggesting that confounding by disease severity was not an issue in the current study.

Strengths of this study include the availability of longitudinal data on metformin prescriptions, which permitted us to reliably estimate the average and cumulative dose as well as the continuous duration of metformin use. In addition, this made it possible to study long-term use of metformin and to test our hypothesis in different ways. Moreover, we have been able to adjust for different important confounders. Limitations of this study include a relatively small sample size, which may be the reason we failed to show an association. Furthermore, only cross-sectional data were available on the arterial stiffness parameters, which makes it impossible to examine causal relationships at this stage.

We showed that dosage and duration of metformin were not associated with aortic stiffness as measured by cfPWV. In addition, we showed that metformin dosage and duration were not associated with lower carotid stiffness as measured by distensibility coefficient and YEM. The present results showed no beneficial effect of metformin dosage or duration on arterial stiffness in middle-aged patients with T2D using metformin as compared with nonmetformin users. Alternatively, metformin may exerts its cardio-protective effects via other pathways, for example, via its beneficial effects on endothelial dysfunction and(or) lowgrade inflammation [30].

\section{AGKNOWLEDGEMENTS}

We thank all participants of the Maastricht Study, their community pharmacist and the Apothekers Vereniging Maastricht for their cooperation.

The current study was supported by the European Regional Development Fund via OP-Zuid, the Province of Limburg, the Dutch Ministry of Economic Affairs (grant 310.041), Stichting De Weijerhorst (Maastricht, the Netherlands), the Pearl String Initiative Diabetes (Amsterdam, the Netherlands), the Cardiovascular Center (CVC, Maastricht, the Netherlands), Cardiovascular Research Institute Maastricht (CARIM, Maastricht, the Netherlands), School for Public Health and Primary Care (CAPHRI, Maastricht, the Netherlands), School for Nutrition, Toxicology and Metabolism (NUTRIM, Maastricht, the Netherlands), 
Stichting Annadal (Maastricht, the Netherlands), Health Foundation Limburg (Maastricht, the Netherlands) and by unrestricted grants from Janssen-Cilag B.V. (Tilburg, the Netherlands), Novo Nordisk Farma B.V. (Alphen aan den Rijn, the Netherlands) and Sanofi-Aventis Netherlands B.V. (Gouda, the Netherlands).

\section{Conflicts of interest}

J.D., H.O., M.S., C.v.K., K.R., S.S., C.S., N.S., A.K., C.S., R.H. declare no conflicts of interest. F.d.V reports that he supervises a PhD student who is employed at Roche Pharmaceuticals. He has not received any fees or reimbursement for this. J.v.B. reports grants and personal fees from Eli Lilly, grants and personal fees from Amgen, grants from Will Pharma, outside the submitted work.

\section{REFERENGES}

1. Chen L, Magliano DJ, Zimmet PZ. The worldwide epidemiology of type 2 diabetes mellitus - present and future perspectives. Nat Rev Endocrinol 2011; 8:228-236.

2. Aronson D. Cross-linking of glycated collagen in the pathogenesis of arterial and myocardial stiffening of aging and diabetes. $J$ Hypertens 2003; 21:3-12.

3. Stehouwer CD, Henry RM, Ferreira I. Arterial stiffness in diabetes and the metabolic syndrome: a pathway to cardiovascular disease. Diabetologia 2008; 51:527-539.

4. Prenner SB, Chirinos JA. Arterial stiffness in diabetes mellitus, Atherosclerosis 2015; 238:370-379.

5. Laurent S, Cockcroft J, Van Bortel L, Boutouyrie P, Giannattasio C, Hayoz D, et al., European Network for Noninvasive Investigation of Large Arteries. Expert consensus document on arterial stiffness: methodological issues and clinical applications. Eur Heart J 2006; 27:2588-2605.

6. Kinaan M, Ding H, Triggle CR. Metformin: an old drug for the treatment of diabetes but a new drug for the protection of the endothelium. Med Princ Pract 2015; 24:401-415.

7. UK Prospective Diabetes Study Group. Tight blood pressure control and risk of macrovascular and microvascular complications in type 2 diabetes (UKPDS 38). BMJ 1998; 317:703-713.

8. Abbasi F, Chu JW, McLaughlin T, Lamendola C, Leary ET, Reaven GM. Effect of metformin treatment on multiple cardio-vascular disease risk factors in patients with type 2 diabetes mellitus. Metabolism 2004; 53:159-164.

9. Mather KJ, Verma S, Anderson TJ. Improved endothelial function with metformin in type 2 diabetes mellitus. J Am Coll Cardiol 2001; 37:1344-1350.

10. Arunachalam G, Samuel SM, Marei I, Ding H, Triggle CR. Metformin modulates hyperglycaemia-induced endothelial senescence and apoptosis through SIRT1. Br J Pharmacol 2014; $171: 523-535$.

11. Kooy A, de Jager J, Lehert P, Bets D, Wulffelé MG, Donker AJ, Stehouwer CD. Long-term effects of metformin on metabolism and microvascular and macrovascular disease in patients with type 2 diabetes mellitus. Arch Intern Med 2009; 169:616-625.

12. Lamanna C, Monami M, Marchionni N, Mannucci E. Effect of metformin on cardiovascular events and mortality: a meta-analysis of randomized clinical trials. Diabetes Obes Metab 2011; 13:221-228.
13. Chakraborty A, Chowdhury S, Bhattacharyya M. Effect of metformin on oxidative stress, nitrosative stress and inflammatory biomarkers in type 2 diabetes patients. Diabetes Res Clin Pract 2011; 93:56-62.

14. Yoshida N, Okumura K, Aso Y. High serum pentosidine concentrations are associated with increased arterial stiffness and thickness in patients with type 2 diabetes. Metabolism 2005; 54:345-350.

15. van Bussel BC, Schouten F, Henry RM, Schalkwijk CG, de Boer MR, Ferreira I, et al. Endothelial dysfunction and low-grade inflammation are associated with greater arterial stiffness over a 6-year period. Hypertension 2011; 58:588-595.

16. Schram M, Sep SJ, Kallen van der CJ, Dagnelie PC, Koster A, Schaper N, et al. The Maastricht Study: an extensive phenotyping study on determinants of type 2 diabetes, its complications and its comorbidities. Eur J Epidemiol 2014; 29:439-451.

17. WHO's ATC/DDD index 2016, accessible through: https://www. whocc.no/atc_ddd_index_and_guidelines/atc_ddd_index [Accessed 18 January 2016]

18. Van Wijk BL, Klungel OH, Heerdink ER, de Boer A. The association between compliance with antihypertensive drugs and modification of antihypertensive drug regimen. J Hypertens 2004; 22:1831-1837.

19. Van Bortel LM, Laurent S, Boutouyrie P, Chowienczyk P, Cruickshank $\mathrm{JK}$, De Backer T, et al. Expert consensus document on the measurement of aortic stiffness in daily practice using carotid-femoral pulse wave velocity. J Hypertens 2012; 30:445-448.

20. Hermeling E, Reesink KD, Kornmann. Reneman RS, Hoeks AP. The dicrotic notch as alternative time-reference point to measure local pulse wave velocity in the carotid artery by means of ultrasonography. J Hypertens 2009; 27:2028-2035.

21. Willekes C, Hoeks AP, Bots ML, Brands PJ, Willigers JM, Reneman RS. Evaluation of off-line automated intima-media thickness detection of the common carotid artery based on M-line signal processing. Ultrasound Med Biol 1999; 25:57-64.

22. Reneman RS, Meinders JM, Hoeks AP. Noninvasive ultrasound in arterial wall dynamics in humans: what have we learned and what remains to be solved. Eur Heart J 2005; 26:960-966.

23. Inker LA, Schmid CH, Tighiouart H, Eckfeldt JH, Feldman HI, Greene T, et al. Estimating glomerular filtration rate from serum creatinine and cystatin C. N Engl J Med 2012; 367:20-29.

24. Reference Values for Arterial Stiffness' Collaboration. Determinants of pulse wave velocity in healthy people and in the presence of cardiovascular risk factors: 'establishing normal and reference values'. Eur Heart J 2010; 31:2338-2350.

25. Machado HA, Vieira M, Cunha MR, Correia MR, Fukui RT, Santos RF, et al. Metformin, but not glimepiride, improves carotid artery diameter and blood flow in patients with type 2 diabetes mellitus. Clinics (Sao Paulo) 2012; 67:711-717.

26. Dell'Oro R, Maloberti A, Nicoli F, Villa P, Gamba P, Bombelli M, et al. Long-term Saxagliptin treatment improves endothelial function but not pulse wave velocity intima-media thickness in type 2 diabetic patients. High Blood Press Cardiovasc Prev 2017; 24:393-400.

27. Hou X, Song J, Li XN, Zhang L, Wang X, Chen L, Shen YH. Metformin reduces intracellular reactive oxygen species levels by upregulating expression of the antioxidant thioredoxin via the AMPK-FOXO3 pathway. Biochem Biophys Res Commun 2010; 396:199-205.

28. Sena CM, Matafome P, Louro T, Nunes E, Fernandes R, Seiça RM. Metformin restores endothelial function in aorta of diabetic rats. $\mathrm{Br} \mathrm{J}$ Pharmacol 2011; 163:424-437.

29. Tucker GT, Casey C, Phillips PJ, Connor H, Ward JD, Woods HF. Metformin kinetics in healthy subjects and in patients with diabetes mellitus. Br J Clin Pharmacol 1981; 12:235-246.

30. Riksen NP, Tack CJ. The cardiovascular effects of metformin: lost in translation? Curr Opin Lipidol 2014; 25:446-451. 